\title{
Preparation and Application of Mesoporous Nanotitania Photocatalysts Using Different Templates and pH Media
}

\author{
S. M. Abdel-Azim, ${ }^{1}$ A. K. Aboul-Gheit, ${ }^{1}$ S. M. Ahmed, ${ }^{1}$ \\ D. S. El-Desouki, ${ }^{1}$ and M. S. A. Abdel-Mottaleb ${ }^{2}$ \\ ${ }^{1}$ Egyptian Petroleum Research Institute, Nasr City, Cairo 11787, Egypt \\ ${ }^{2}$ Nanophotochemistry and Solarchemistry Labs, Chemistry Department, Faculty of Science, \\ Ain Shams University, Abbassia, Cairo 11566, Egypt
}

Correspondence should be addressed to M. S. A. Abdel-Mottaleb; phochem08@photoenergy.org

Received 16 September 2013; Accepted 10 December 2013; Published 4 February 2014

Academic Editor: Luminita Andronic

Copyright ( 2014 S. M. Abdel-Azim et al. This is an open access article distributed under the Creative Commons Attribution License, which permits unrestricted use, distribution, and reproduction in any medium, provided the original work is properly cited.

\begin{abstract}
Mesoporous nanotitania photocatalysts were prepared by sol-gel method in acidic or basic media. Three types of surfactants, namely, cetyltrimethylammonium bromide, sodium dodecylbenzenesulfonate, and nonylphenol ethoxylate, were used as templating agents. The effects of surfactant type and $\mathrm{pH}$ on the morphology, particle size, surface area, pore-size distribution, UV-Vis absorbance, and $\mathrm{TiO}_{2}$ phase transformation were traced by SEM, TEM, BET, and XRD. In absence of surfactants, XRD revealed $54.5 \%$ anatase at $\mathrm{pH}$ 3-4 and $97.0 \%$ at $\mathrm{pH}$ 7-9. In presence of surfactant, phase transformation of anatase has been significantly inhibited such that anatase amounts to $82-100 \%$ in acidic media. In basic media, the brookite phase appeared in low concentrations (8-15\%) while rutile totally disappeared. The photocatalytic performance of the synthesized catalysts was tested via naphthalene degradation, which exhibited high activity in visible irradiation $(>400 \mathrm{~nm})$. The data obtained indicate that the surface area and pore volume of the current catalysts are the most effective factors for photocatalytic performance. Nevertheless, at the low $\mathrm{pH}$ (acidic) range, the CTAB templated catalyst gave the highest surface area $\left(86.7 \mathrm{~cm}^{3} / \mathrm{g}\right)$, which is mainly assigned to acquiring the highest photocatalytic degradation of naphthalene ( $97 \%$ after $4 \mathrm{~h}$ irradiation time)
\end{abstract}

\section{Introduction}

The properties of nanocrystals depend not only on their chemical compositions, but also on their structures, phases, shapes, sizes, and dimensionality [1]. Since the discovery of photocatalysis, titanium oxide $\left(\mathrm{TiO}_{2}\right)$ has attracted signification research attention due to its broad applications in the fields of water and air purification [2-4]. Also, $\mathrm{TiO}_{2}$ has versatile potential applications besides catalysis, such as in solar-energy conversion, lithium storage, and optoelectronic devices. Many studies have described the shape and size control of inorganic nanoparticles by using conventional synthesis methods such as the sol-gel method and hydrothermal method. The sol-gel method has many advantages over other methods mainly because of the following: good homogeneity, ease of composition control, low processing temperature, large area coatings, low equipment cost, and good optical properties [5]. Mesoporous $\mathrm{TiO}_{2}$ has better properties in many respects than ordinary $\mathrm{TiO}_{2}$ because of its high specific surface area, uniform pore diameter, potential role in enhancing the light absorbance, and the accessibility of reactants to the active catalytic sites [6]. Mesoporous $\mathrm{TiO}_{2}$ has been prepared as bulk powders and films [6,7]. An interesting method to fabricate highly porous materials with desired pore structure and size for target specific applications is the use of amphiphilic organic molecules such as surfactants and block copolymers as pore directing agents in sol-gel methods [8]. Our motivation is to explore an effective technique to construct the oriented organization of nanoparticles, which is based on creating an interfacial interaction by chemical modification on the surfaces of nanoparticles (or micelle formation, that is, form colloidal-size cluster in solution called micelles which depend on surfactant concentration and salt concentration). Park et al. [9] have reported the 
preparation of mesoporous titania through a modified solgel process in presence of CTAB surfactant. Shalan et al. [10] synthesized anatase $\mathrm{TiO}_{2}$ nanorods with controlled size for dye-sensitized solar cells (DSSCs) via hydrothermal route at low hydrothermal temperature of $100^{\circ} \mathrm{C}$ for $24 \mathrm{~h}$. A number of formation mechanism models have been proposed to explain the growth process of nanostructured materials from the inorganic precursor in the presence of surfactants selfassembles [11]. Transition metal oxides have been prepared in mesoporous forms using the amphiphilic surfactant templates such as triblock copolymers and ionic surfactants such as CTAB and neutral amines [7].

Naphthalene $\left(\mathrm{NP} \mathrm{C}_{10} \mathrm{H}_{8}\right)$ is a polycyclic aromatic hydrocarbon $(\mathrm{PAH})$, which is a widespread environmental contaminant because of its generation as a combustion byproduct and use as a pesticide and pesticide synthesis intermediate and as component of fuels such as JP-8 [12]. Since it is the most water-soluble PAH (solubility $25-30 \mathrm{mg} \mathrm{L}^{-1}$ at ambient temperature), it is the dominant one in water. It has been considered as possibly carcinogenic to humans and it has both acute and chronic effects on humans and animal health. So, removing of naphthalene from water is urgently needed and possible via many techniques. Remediation and treatment of water, soil, or wastewater from PAH include conventional methods as homogeneous methods, bioremediation [13], hydrogenation [14], and ozonation, [15] and heterogeneous methods, photocatalytic degradation, fenton heterogeneous catalytic system [16], and metal oxides [17]. Advanced oxidation processes (AOPs) [18] present many advantages which are faster and can be achieved under direct sunlight making it cheaper to operate than other techniques. The total destruction of naphthalene using metal oxides with various supporting materials was carried out [19, 20]. Photocatalytic oxidation of naphthalene solution using various kinds of industrial titanium dioxide powders having anatase and rutile structure was tested as photocatalysts by Ohno et al. [21].

Other authors investigated changing the conditions they applied in preparing the nanocatalysts for use as active photocatalysts. In our work, we categorized the different types of surfactants to be used at different $\mathrm{pH}$ values (acidic and basic media). This scheme of work makes us able to illustrate a wide understanding of surface-active templates in nanophotocatalysts.

Therefore, in this work, we modified the sol-gel method through using three types of surfactants (cationic, anionic, or nonionic) in acidic or basic media for controlling the phase structure, size, crystallinity, mesoporosity, and hence the light absorptivity in the visible range. The photocatalytic activity of the nanostructured mesoporous $\mathrm{TiO}_{2}$ catalyst has been tested in photodegradation of naphthalene as a water pollutant model compound.

\section{Experiment}

2.1. Materials. In the current experiments, all chemicals were used as received. Titanium (IV) isopropoxide (TTIP) (97\% Aldrich), isopropanol (i-PrOH, Fisher), acetic acid
(Fisher), ammonium hydroxide, cetyltrimetylammonium bromide (CTAB), sodium dodecylbenzenesulfonate (DBS), nonylphenol ethoxylate (NPE), and deionized water were used to prepare the solutions in our experiments. Naphthalene (Panreac, 98\%) was used as a pollutant, acetonitrile and deionized water were used as HPLC eluent.

\subsection{Synthesis of the Current Titania Catalysts. Mesoporous} nanocrystalline titania was prepared under controllable solgel process using titanium alkoxide in absence or presence of micellar surfactants as templating agents [22]. The molar ratio of surfactant/TTIP/i-PrOH/acetic acid or ammonium hydroxide was $R: 4: 45: 6$, where $R$ is the surfactant concentration was which 0 or 1 at $\mathrm{pH} 3-4$ in acetic acid or 89 in ammonia solution. Hydrolysis and polymerization took place in this mixture producing a transparent, homogeneous, and stable $\mathrm{TiO}_{2}$ sol. After gelation for $24 \mathrm{~h}$, the gel was dried overnight at $80^{\circ} \mathrm{C}$. The recovered powder was intermittently washed with deionized water and isopropanol five times followed by separation in a centrifuge under $10000 \mathrm{rpm}$ to remove the surfactant. The resulted filtered cake was dried overnight at $100^{\circ} \mathrm{C}$ and then calcined at $550^{\circ} \mathrm{C}$ for $4 \mathrm{~h}$ to remove the remaining surfactant and consequently produce the desired $\mathrm{TiO}_{2}$ nanoparticles photocatalyst (Scheme 1). The nomenclature was designed according to the $\mathrm{pH}$ range and the used surfactant. Preparation catalysts in acidic and basic medium were as follows: (1) without surfactant: A and B, (2) in presence of surfactants, CTAB-A, DBS-A, and NPE-A, in acidic medium, and (3) CTAB-B, DBS-B, and NPE-B in basic medium.

2.3. Photocatalytic Activity Testing. The photocatalytic activities of the synthesized catalysts were evaluated for naphthalene degradation in an aqueous solution using a tungsten lamp $(300 \mathrm{~W})$ under $300-800 \mathrm{~nm}$ irradiation for 4 hours. In each experiment, a suspension with a volume of $200 \mathrm{~mL}$ containing naphthalene concentration of $80 \mu \mathrm{mol} \mathrm{L}{ }^{-1}(10 \mathrm{ppm})$ and $\mathrm{a} \mathrm{TiO}_{2}$ catalyst powder of $2.5 \mathrm{~g} \mathrm{~L}^{-1}$ was placed in the Pyrex photoreactor under continuous stirring with a magnetic stirrer. The temperature was maintained at $20^{\circ} \mathrm{C}$ using cooling thermostat because of naphthalene volatility. Prior to illumination, the current suspension was magnetically stirred in the dark for $30 \mathrm{~min}$ to reach an adsorption/desorption equilibrium between the photocatalyst and naphthalene. A fixed quantity of the solution was withdrawn at regular time intervals, centrifuging the retrieved samples at 10,000 rpm.

2.4. Physical Characterization of the $\mathrm{TiO}_{2}$ Catalysts. Identification of the prepared $\mathrm{TiO}_{2}$ powdered phases under the different preparation conditions at $\mathrm{pH}$ 3-4 or $\mathrm{pH}$ 8-9 with and without surfactants was examined by powder X-ray diffraction (XRD) analysis using Analytical $\left\{X^{\prime}\right.$ PERT PROMPD $\}$ $\mathrm{X}$-ray diffractometer, $\mathrm{CuK} \alpha$ radiation of wavelength $\lambda=$ $1.5406 \AA$, rating of $40 \mathrm{KV}, 40 \mathrm{~mA}$, step size $=0.02$, and scan step time of $0.4 \mathrm{sec}$ in the $2 \theta$ range $10-80$.

The morphology of the samples was checked by using transmission electron microscopy (TEM). The microstructures of the synthesized PANIs were examined by TEM 


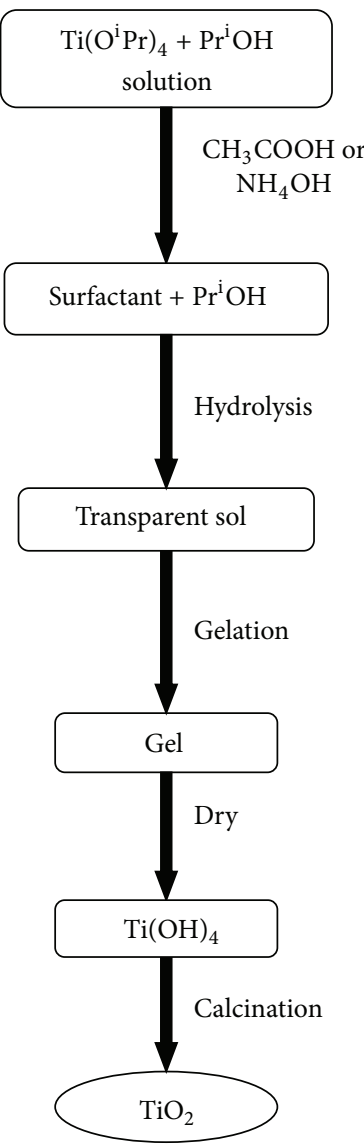

Scheme 1: Preparation of $\mathrm{TiO}_{2}$ photocatalysts.

(Tokyo, Japan) on a JEOL JEM-2000EX (Tokyo, Japan) at an accelerating voltage of $100 \mathrm{kV}$ and scanning electron microscopy (SEM). The emission SEM (Tokyo, Japan) was performed with a JEOL 5400 (Tokyo, Japan).

The surface area was determined from nitrogen adsorption-desorption isotherms at liquid nitrogen temperature $(77 \mathrm{~K})$ using a Quantachrome AS1Win version 2.01 instrument. The $\mathrm{TiO}_{2}$ samples were outgassed for 3 hours at $150^{\circ} \mathrm{C}$. The Brunauer-Emmett-Teller (BET) method was used for surface area calculation, while pore-size distribution (pore diameter and volume) was determined by the Barrett-JoynerHalenda $(\mathrm{BJH})$ method.

Diffuse Reflectance Spectroscopy. Visible-ultraviolet spectra were obtained by diffuse reflectance spectroscopy by using a Shimadzu UV-2401 PC instrument. $\mathrm{BaSO}_{4}$ was the reference sample and the spectra were recorded in the range 200$800 \mathrm{~nm}$.

For photocatalytic activity measurement, high performance liquid chromatography (HPLC) using HPLC Waters 600 apparatus, equipped with an autosampler (Waters 717 plus) and a dual wavelength absorbance diode array detector (Waters 4487) set at $254 \mathrm{~nm}$, was used with C18 $5 \mu \mathrm{m}, 4.6 \mathrm{~mm}$ $\times 250 \mathrm{~mm}$ column (part no. 186004117) purchased from water USA. The mobile phase was HPLC grade water/acetonitrile $(30 / 70)$ operating at a flow rate of $1 \mathrm{~cm}^{3} \mathrm{~min}^{-1}$.

\section{Results and Discussion}

3.1. Effect of Surfactants Type and $\mathrm{pH}$ on Particle Size Distribution of $\mathrm{TiO}_{2}$. In order to prevent the growth of nano- $-\mathrm{TiO}_{2}$, the influence of the surfactant types on the particle size distribution of $\mathrm{TiO}_{2}$, including anionic surfactant DBS, cationic surfactant CTAB, and nonionic surfactant NPE, is studied. These surfactants assist reducing the particle size of $\mathrm{TiO}_{2}$ during their sorption on the surface of nanoparticles. The reaction depends on the interfacial energy among particles which prevents the aggregation of powders from the static repulsion and special hindrance. To study the influence of reaction conditions on the morphology and phases of $\mathrm{TiO}_{2}$, controlled experiments have been designed with varied types of surfactants and $\mathrm{pH}$. The $\mathrm{pH}$ of solution has a significant impact on the $\mathrm{TiO}_{2}$ morphology. The result obtained shows that $\mathrm{TiO}_{2}$ nanoparticles with different sizes can be formed under the conditions of hydrolysis of titanium isopropoxide at two different values, $\mathrm{pH}=3-4$ (acidic medium) and $\mathrm{pH}$ =8-9 (alkaline medium). At different $\mathrm{pH}$ of the system, the diameter of nanoparticles becomes different, since, in acidic media, the concentration of $\mathrm{H}^{+}$becomes higher. The oxygen atom in $\mathrm{Ti}-\mathrm{O}$ which has a lone electron pair will easily form hydrogen bond with the $\mathrm{H}^{+}$. Thus the intensity of Ti-O bonds is weakened and the system becomes easier to hydrolyze with higher speed of $\mathrm{TiO}_{2}$ nucleation. The products are smaller while the amount of nucleus is larger [23]. 
TABLE 1: Physical characterization of the current catalysts.

\begin{tabular}{|c|c|c|c|c|c|}
\hline Catalyst & Surface area $\left(\mathrm{m}^{2} / \mathrm{g}\right)$ & Crystal phase \% & Average TEM (nm) & Absorbance (nm) & Activity \% \\
\hline A & 16 & $\begin{aligned} A & =54.63 \\
R & =45.37\end{aligned}$ & 14 & 390 & 37 \\
\hline CTAB-A & 86.71 & $A=100$ & 8 & 400 & 97 \\
\hline DBS-A & 57.49 & $\begin{aligned} A & =82.99 \\
R & =17.01\end{aligned}$ & 9 & 395 & 85 \\
\hline NPE-A & 43.01 & $\begin{array}{c}A=94.73 \\
R=5.27\end{array}$ & 9 & 390 & 24 \\
\hline B & 12 & $\begin{array}{c}A=96.45 \\
R=3.54\end{array}$ & 11.5 & 380 & 20 \\
\hline CTAB-B & 62.11 & $\begin{aligned} A & =84.71 \\
B & =15.29\end{aligned}$ & 11 & 390 & 70.5 \\
\hline DBS-B & 67.21 & $A=100$ & 16 & 410 & 83.5 \\
\hline NPE-B & 70.29 & $\begin{array}{c}A=91.72 \\
B=8.28\end{array}$ & 10 & 430 & 91.6 \\
\hline
\end{tabular}

In presence of ammonia (alkaline medium), a complex can be formed with $\mathrm{Ti}^{4+}$ which will facilitate the growth of nuclei and increase the peptizing speed. However, the $\mathrm{TiO}_{2}$ crystal changes from anatase to brookite. So, the size of particles can be controlled by regulating the $\mathrm{pH}$ of solution [24].

3.2. XRD Pattern of $\mathrm{TiO}_{2}$ Nanoparticles. The XRD patterns in Figures 1 and 2 and the data listed in Table 1 show the crystalline phase content in the synthesized catalysts. The XRD patterns illustrate the effect of $\mathrm{pH}$ modifiers (acetic acid and ammonia) in absence or presence of surfactants. The mass fractions of anatase, rutile, and brookite are calculated from the (101) reflection of anatase at $2 \theta=25.48^{\circ}$, the (110) reflection of rutile at $2 \theta=27.58^{\circ}$, and (121) reflection of brookite at $2 \theta=30.8^{\circ}$. The mass fraction of each phase present in the powder was calculated using the equation $x=1+$ $0.8\left(I_{A} / I_{R}\right)^{-1}$, where $x$ is the weight fraction of rutile in the $\mathrm{TiO}_{2}$ and $I_{A}$ and $I_{R}$ are the X-ray intensities of the anatase and rutile peaks, respectively (see Table 1 ). Also, the crystallite size of these phases is calculated applying Scherrer's equation $D=0.9 \lambda / \beta \cos \theta$, where $D$ is the thickness of crystallite, $\lambda$ is $\mathrm{X}$-ray wavelength, $\beta$ is FWHM (full width at half $\max$ ), and $\theta$ is Bragg Angle. The crystallite sizes calculated are in agreement with the particle size measured by TEM.

3.2.1. Effect of $p H$ in Absence of Surfactants. In the XRD pattern (Figure 1) obtained for the $\mathrm{TiO}_{2}$ catalyst prepared using acetic acid as a $\mathrm{pH}$ modifier ( $\mathrm{pH} 3-4)(\mathrm{A})$ gives $54.6 \%$ anatase and $45.4 \%$ rutile forms. Parra et al. [25] have prepared pure anatase phase at $\mathrm{pH}$ 5-6 and reported that, in a stronger acidic medium, the rutile formation would be privileged. On the other hand, when ammonia has been used to adjust the $\mathrm{pH}$ at 8-9 (B), it is found to be $96.4 \%$ anatase and as low as 3.5\% rutile phase. Lim et al. [26] reported that, when $\mathrm{TiO}_{2}$ was prepared using $\mathrm{NH}_{4} \mathrm{OH}$ at $\mathrm{pH} 7-9$, the rutile phase was only observed at calcination temperatures above $500^{\circ} \mathrm{C}$. Hence, it is concluded that the resistance of anatase transformation to

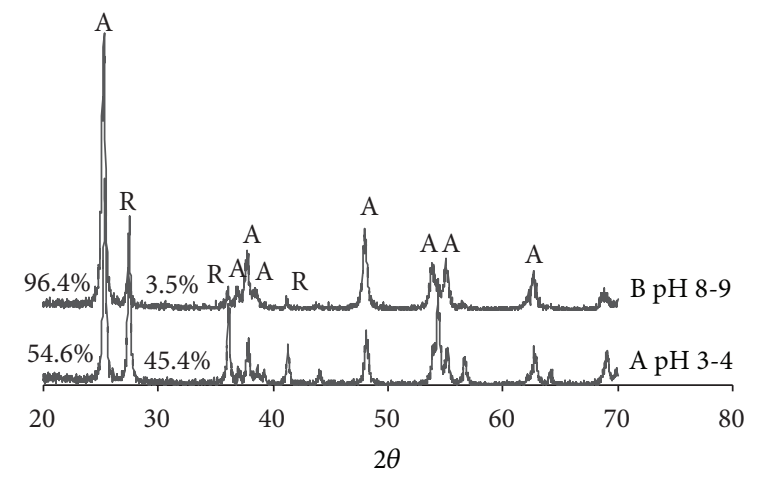

FIgURE 1: X-ray diffraction spectra for $\mathrm{TiO}_{2}$ at different $\mathrm{pH}$.

rutile increases more in basic medium than in acidic medium at the same calcination temperature $\left(550^{\circ} \mathrm{C}\right)$, as with $\mathrm{Hu}$ et al. [27].

3.2.2. Effect of $p H$ in Presence of Surfactants. During the preparation of $\mathrm{TiO}_{2}$ catalysts in presence of different types of surfactants, it is found that the produced $\mathrm{TiO}_{2}$ is completely anatase phase using the cationic surfactant (CTAB) at $\mathrm{pH}$ 3-4 (CTAB-A), whereas, at $\mathrm{pH} \mathrm{9,} \mathrm{in} \mathrm{presence} \mathrm{of} \mathrm{the} \mathrm{same}$ surfactant (CTAB-B), $\mathrm{TiO}_{2}$ has been produced in two phases, anatase $(84.7 \%)$ and brookite (15.3\%). From XRD patterns (Figure 2 and Table 1), it is calculated from the broadening of the peaks that the crystallite size of the prepared $\mathrm{TiO}_{2}$ using the CTAB surfactant in ammonia solution or acetic acid is lower than that produced in absence of surfactant (in Figure 1). Also, the presence of surfactant suppresses the anatase-rutile transformation. In sample CTAB-A, there is no rutile phase while in sample CTAB-B there is a small amount of the brookite phase. Guohui et al. [28] prepared $\mathrm{TiO}_{2}$ powders using CTAB in the presence of ammonium hydroxide. The authors found that, at calcination temperatures below $600^{\circ} \mathrm{C}, \mathrm{TiO}_{2}$ samples display dominantly anatase phase together with a small amount of brookite which is in 


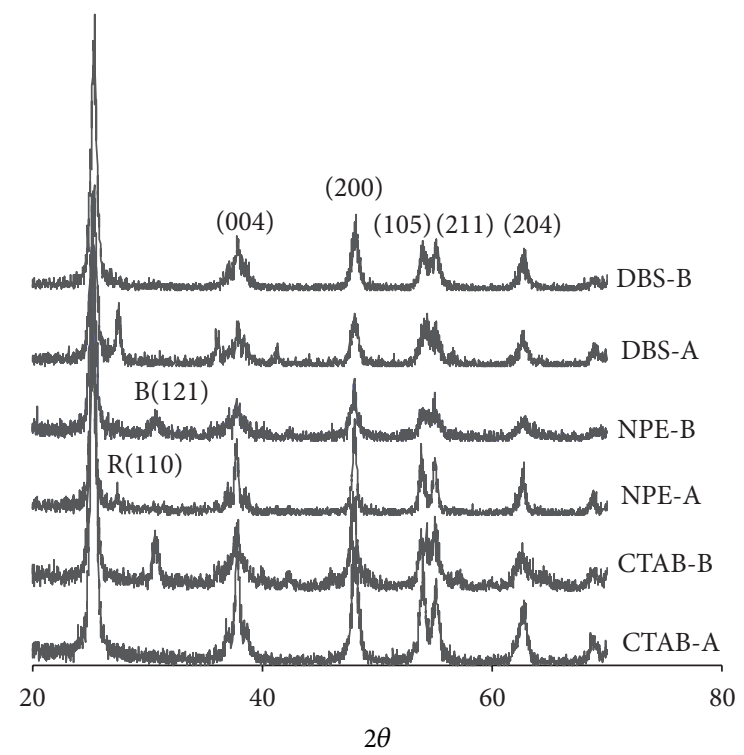

Figure 2: X-ray diffraction spectra for $\mathrm{TiO}_{2}$ at different $\mathrm{pH}$ and surfactants.

agreement with our results. On using the anionic surfactant (DBS), anatase comprises $83.0 \%$ and rutile comprises $17.0 \%$ at pH 3-4 (DBS-A), whereas at pH 8-9 (DBS-B) anatase comprises $100 \%$. Nevertheless, using the nonionic surfactant (NPE), the rutile phase comprises $5.3 \%$ in anatase/rutile mixture at $\mathrm{pH}$ 3-4 (NPE-A), which is less than in the absence of a surfactant. At pH 8-9, the brookite phase appears (8.28\%) while the rutile phase is absent (NPE-B).

3.3. The Morphologies of $\mathrm{TiO}_{2}$ Nanoparticles. The TEM photographs obtained for the current $\mathrm{TiO}_{2}$ samples prepared at different conditions using various types of surfactants are given in Figures 3 and 4. In the acidic medium (at $\mathrm{pH}$ 3-4) while in absence of surfactant, the sample exhibits particles mainly in the form of hexagonal prisms and rhombohedrons (Figure 3). This may be attributed to the presence of sufficient precursor for the reaction to take place. This may help also in obtaining random shapes rather than regular spherical particles. The particle size is varied from 12 to $14 \mathrm{~nm}$ in both acidic and basic media. It is also observed that there is an agglomeration of $\mathrm{TiO}_{2}$ particles associated with low surface area and low pore volume. TEM images show many regions with shadow which have been reported to indicate the formation of curved channels between the packed particles [29]. These observations agree with our $\mathrm{N}_{2}$ adsorption/desorption results (Figure 5), where $\mathrm{H} 3$ hysteresis loops of $\mathrm{TiO}_{2}$ suggest that there are curved channels in the bulk.

From the selected area electron diffraction patterns (SAED) of $\mathrm{TiO}_{2}$ with no surfactant in both basic and acidic media (inset of Figure 3), spotty sharp rings occur which are indicative of polycrystalline materials with high crystallinity. The first five SAED rings represent anatase phase indexed as (101), (004), (200), (105), and (211) (JCPDS no, 21-1272) and rutile phase indexed as (110). This result is in agreement with XRD patterns shown in Figure 1.
The TEM morphology of $\mathrm{TiO}_{2}$ samples prepared using various types of surfactants in either acidic or basic medium is shown in Figure 4. It can be observed that all samples prepared with the aid of surfactant have more dispersed particles than those without surfactants, which could be attributed to the fact that surfactants prevent the aggregation of $\mathrm{TiO}_{2}$ powders [30]. Chen et al. [31] have reported that (1) the surfactants could adhere on the anatase face (101) of $\mathrm{TiO}_{2}$ and therefore it could modify the surface free energy of $\mathrm{TiO}_{2}$ during the titania catalyst preparation and (2) during the removal of a surfactant by successive washing and calcination processes more mesopores were left in $\mathrm{TiO}_{2}$. TEM images give hexagon, diamond, cohexagon, and bullet shapes.

3.4. SEM of $\mathrm{TiO}_{2}$ Nanoparticles. Figure 5 shows the SEM images obtained for current samples. The $\mathrm{TiO}_{2}$ particles obtained during preparation in acidic medium in absence of a surfactant acquire heterogeneous sizes with their surface appearing rough. However, the images obtained for the samples CTAB-A, NPE-A, and DBS-A consist of large numbers of nanoparticles with relatively smooth external surfaces. The relatively smooth external surface of those nanoparticles suggests that they are composed of countless tiny primary nanoparticles. The aggregation of these tiny primary nanoparticles can produce large numbers of interaggregated pores, resulting in a highly mesoporous nanotitania as shown in Figure 5. The effect of applying surfactants on the morphology and microstructure of the mesoporous titania nanoparticles shows that there is shrinkage of the nanoparticles diameters caused by collapse of smaller pores. After washing and calcination for 5 times, the surfactants were completely removed and a porous structure was achieved in the microspheres $[32,33]$.

3.5. The BET Surface Characterization. Figure 6 shows the isotherms obtained for the prepared $\mathrm{TiO}_{2}$ at different $\mathrm{pH}$ values in absence or presence of different templating surfactants. The isotherms are of classical type IV, characteristic for mesoporous materials according to the IUPAC classification [34]. The adsorbed volume at relative pressures below 0.3 is due to monolayer coverage of the surface, while the increase of the relative pressure to $0.4-0.8$ with broad hysteresis loops is due to capillary condensation within mesopores [35].

In presence of the three types of surfactants, the hysteresis loops of the photocatalysts prepared in basic medium at $\mathrm{pH}$ 8-9 appear at a high relative pressure $P / P^{0}$ range of $0.56-$ 0.70 with $\mathrm{H} 1$ and $\mathrm{H} 3$ type loops, which correspond to slit shape pores [29]. However, using the same catalysts prepared in acidic medium at $\mathrm{pH} 3-4$, the hysteresis loops appear at $P / P^{0}$ range of $0.4-0.6$ with $\mathrm{H} 2$ type loops associated with ink-bottle pores [36]. The surface area, pore volume, and the average pore size of the catalysts are summarized in Table 1. In the presence of anionic and nonionic surfactants, the surface area and pore volume of the photocatalysts prepared at $\mathrm{pH} 3$ 4 are higher than those prepared at $\mathrm{pH} 8-9$, indicating higher porosity [32]. In case of using the cationic surfactant (CTAB) at $\mathrm{pH} 3-4$, higher surface area and pore volume have been obtained. 


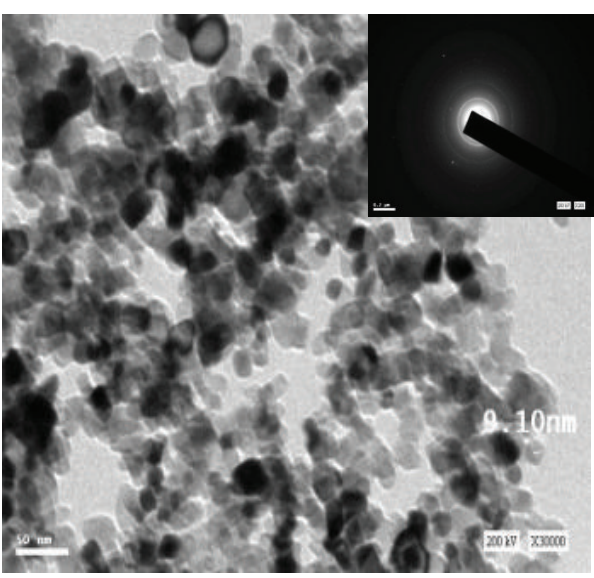

(a)

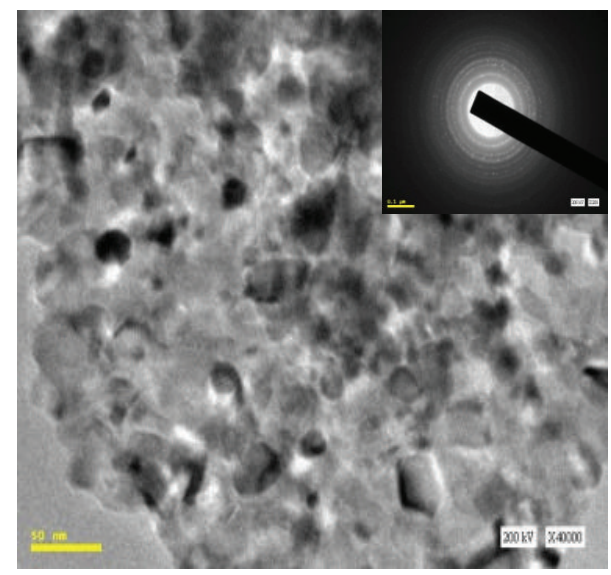

(b)

Figure 3: TEM images of the $\mathrm{TiO}_{2}$ at different $\mathrm{pH}$.

Pore-size distribution was calculated according to the BJH method applying the desorption branch of the isotherm. Figure 7 shows that the pore-size distribution values occupy a broader pore-size range on using the preparation in basic medium (40-180 A) relative to that using the acidic medium (40-120 $\AA$ ). It is observed that the catalyst with the widest pore-size distribution acquires higher surface area and pore volume, as in the case of using CTAB-A catalyst. This agrees with the results of Sasikala et al. [37]. The pore-size range of the synthesized $\mathrm{TiO}_{2}$ catalysts in acidic medium can be arranged in the surfactant order as follows: CTAB > NPE > DBS, whereas synthesis in the basic medium can be arranged in the surfactant order as follows: NPE > DBS > CTAB.

3.6. UV-Vis Diffuse Reflectance Spectra. Figure 8 displays the $\mathrm{UV}$-vis reflectance spectra obtained for $\mathrm{TiO}_{2}$ nanoparticles prepared under different conditions, namely, $\mathrm{pH}$ change and absence or presence of surfactants. All samples gave significant red shift towards the visible light region (385$430 \mathrm{~nm}$ ) which indicates the suitability for applying solar irradiation since the absorbance is related to the sample morphology, surface area, particle size, and crystal phase composition of the particles. The catalysts prepared in absence of surfactants give absorbances at 390 and 385 at pH 3-4 and 8-9, respectively, which is due to the presence of the anatase and rutile of $\mathrm{TiO}_{2}$ phases [38]. However, the absorption edge is shifted to a longer wavelength with increasing the fraction of rutile phase that acquires a smaller band gap $(3.0 \mathrm{eV})$ than that of the anatase phase $(3.2 \mathrm{eV})$. From Figure 8 , the largest red shift is caused by CTAB in acidic medium $(400 \mathrm{~nm})$ whereas NPE causes a higher shift in the basic medium $(430 \mathrm{~nm})$. This is attributed to high surface area, improved grain size [39], pore volume, and the coexistence of anatase and brookite in the $\mathrm{TiO}_{2}$ which cause a decrease of the band gap energy $[40,41]$. Moreover, a trace residue of organic compounds or remaining surfactant [42] would have contributed to increasing the red shift. The band gap energy, $E_{\mathrm{g}}$, of the photocatalysts is assigned to the intrinsic electron transition from the valence band (VB) to the conduction band (CB). $E_{\mathrm{g}}$ values were determined using the absorption UV-vis spectra (Table 1). The optical energy band gap was calculated using the relationship $E_{\mathrm{g}}=h \cdot c / \lambda=$ $1240 / \lambda$ [43], where $E_{\mathrm{g}}$ is the band gap (eV) and $\lambda$ is the wavelength of the absorption edges in the spectrum $(\mathrm{nm})$.

3.7. Photodegradation of Naphthalene on the Catalysts. In this work, the decrease of naphthalene in the dark for the initial $30 \mathrm{~min}$ is taken as the primary adsorption on the catalyst surface. The adsorption capacity is found to increase as surface area increases (Table 1). Naphthalene removal comprises as high as $35 \%$ on CTAB-A, whereas it is only $12 \%$ on NPE-A catalyst. It can be suggested that, as the number of $\mathrm{Ti}^{4+}$ active sites on the surface increases, the rate of electron transfer and adsorption of the pollutant molecules increases [44]. Hao and Zhang [45] reported that an increase of surface area and porosity of the catalyst can reduce the internal mass transfer limitation of the pollutant to the active sites.

Figure 9 shows that, in absence of any templating agent, the photoactivity of the current catalysts is relatively low (20.0\% in basic medium and $37.1 \%$ in acidic medium). This can be attributed to acquiring very low surface area $\left(12.0 \mathrm{~m}^{2} \mathrm{~g}^{-1}\right.$ and $16.3 \mathrm{~m}^{2} \mathrm{~g}^{-1}$, resp.) and very low pore volume $\left(0.0144 \mathrm{~cm}^{3} \mathrm{~g}^{-1}\right.$ and $0.0146 \mathrm{~cm}^{3} \mathrm{~g}^{-1}$, resp.). Furthermore, the rutile formation is as appreciable being $45.4 \%$ in acidic medium and $3.5 \%$ in the basic medium. On the other hand, the catalyst prepared using CTAB as a templating agent in acidic medium exhibits the highest activity all over the present study for the photodegradation of naphthalene ( $97 \%$ after $180 \mathrm{~min}$ ) which may be attributed to acquiring the highest surface area $\left(86.7 \mathrm{~m}^{2} \mathrm{~g}^{-1}\right)$ and the highest pore volume $\left(0.0569 \mathrm{~cm}^{3} \mathrm{~g}^{-1}\right)$ among all current catalysts. Moreover, this catalyst is composed of $100 \%$ anatase phase besides acquiring a particle size as low as $8.0 \mathrm{~nm}$. Furthermore, Figure 8 shows that the largest red shift obtained using this 


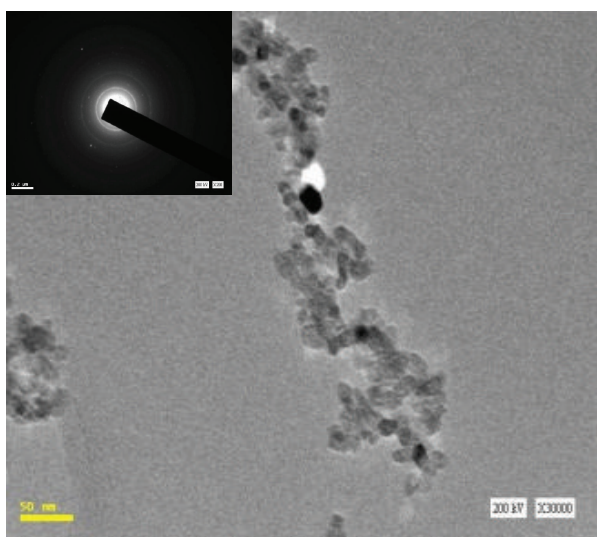

(a)

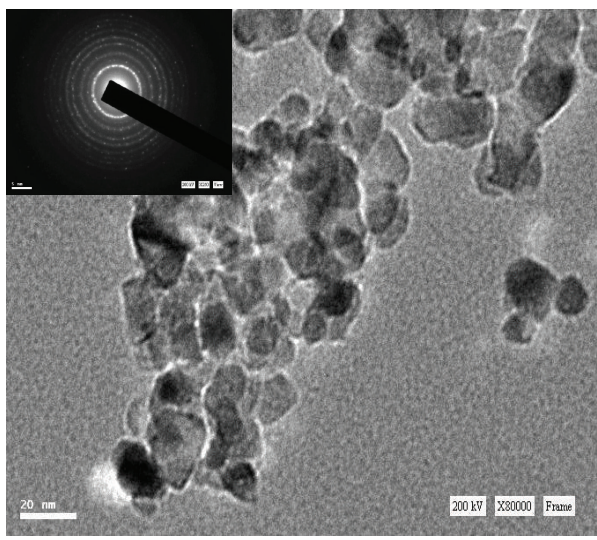

(c)

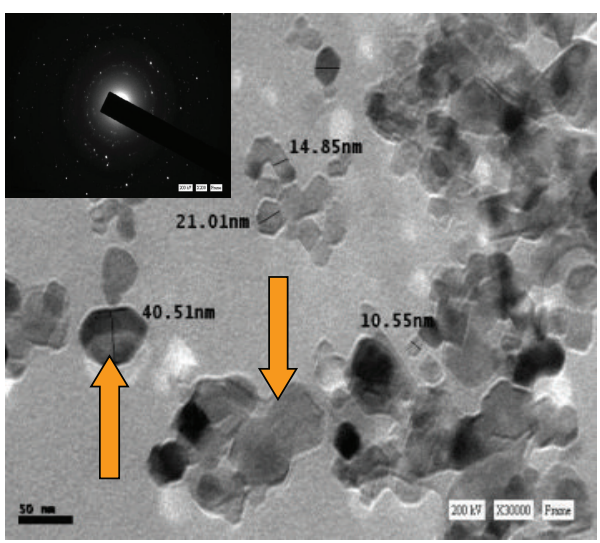

(e)

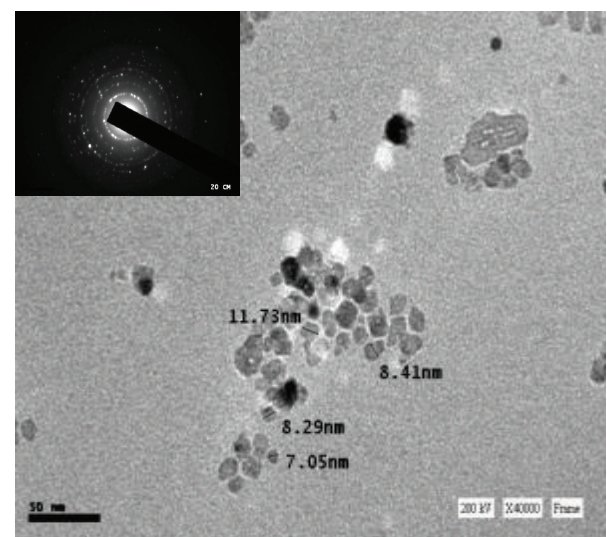

(b)

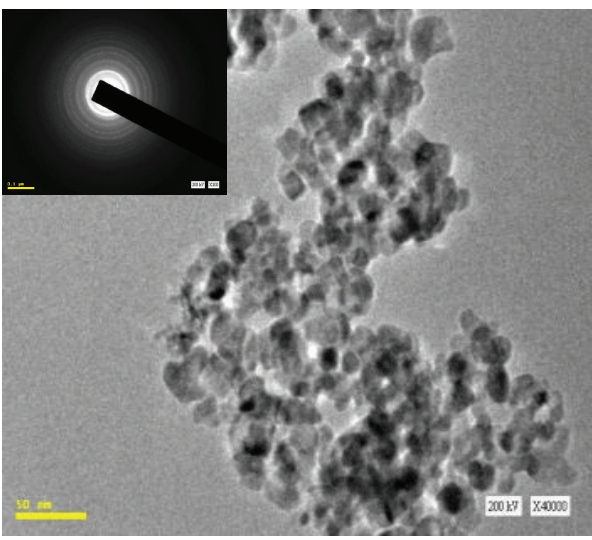

(d)

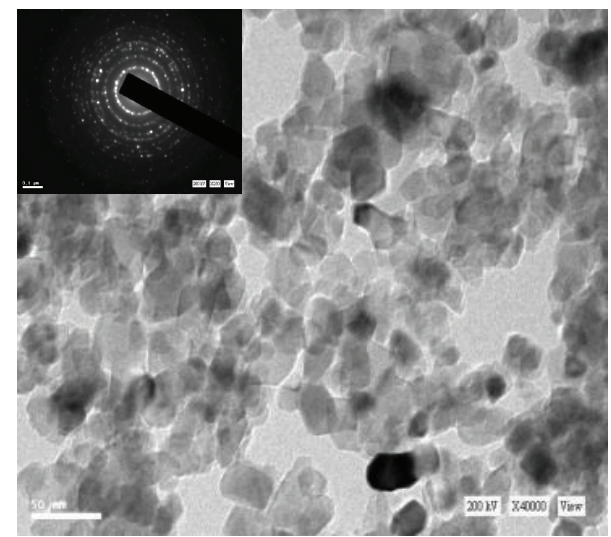

(f)

Figure 4: TEM images of the $\mathrm{TiO}_{2}$ at different $\mathrm{pH}$ and different surfactants. (a) CTAB-A, (b) DBS-A, (c) NPE-A, (d) CTAB-B, (e) DBS-B, and (f) NPE-B.

catalyst appears at $400 \mathrm{~nm}$ indicating a shift towards reducing the band gab from 3.2 to $3.1 \mathrm{ev}$ which is a great privilege for applying visible (solar) irradiation rather than applying UV irradiation. On the other hand, in the basic medium using the same templating agent (CTAB) while keeping the other variables unchanged, a lower photoactivity has been encountered (71.0\%), most expectedly due to its lower surface area $\left(60.1 \mathrm{~m}^{2} \mathrm{~g}^{-1}\right)$ and lower pore volume $\left(0.0309 \mathrm{~m}^{2} \mathrm{~g}^{-1}\right)$ as well as acquiring a significant quantity of brookite.

\section{Conclusion}

The current $\mathrm{TiO}_{2}$ photocatalysts have been prepared by solgel method using Ti-alkoxide as precursor, in acidic or basic media in absence or presence of different surfactants (templates). XRD analysis showed that addition of surfactants suppressed the transformation of anatase to rutile phase. All catalysts exhibited activities in the visible range at various levels. In both acidic and basic media, in absence of 


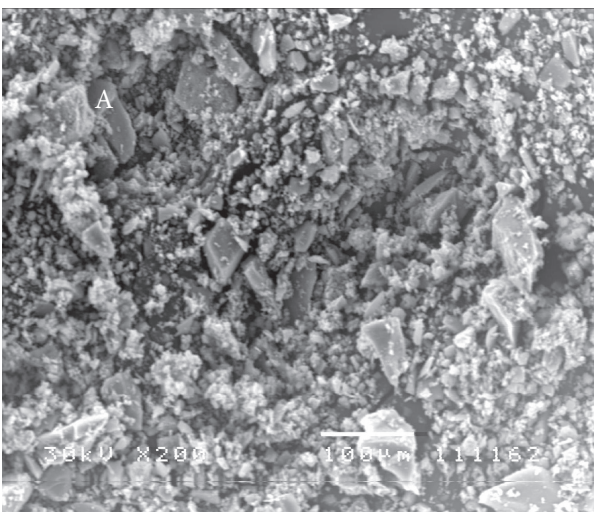

(a)

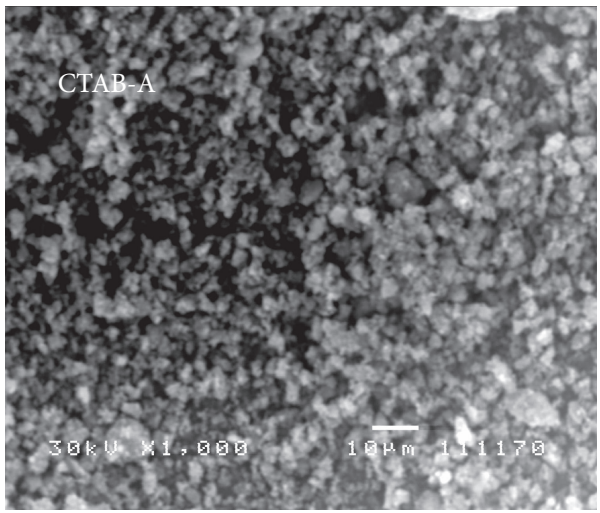

(c)

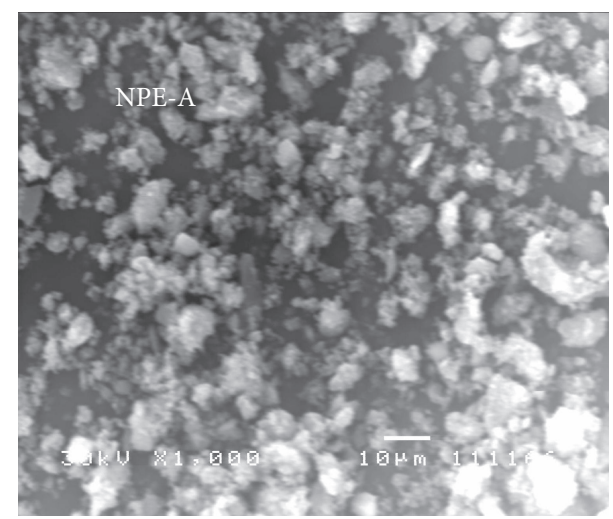

(b)

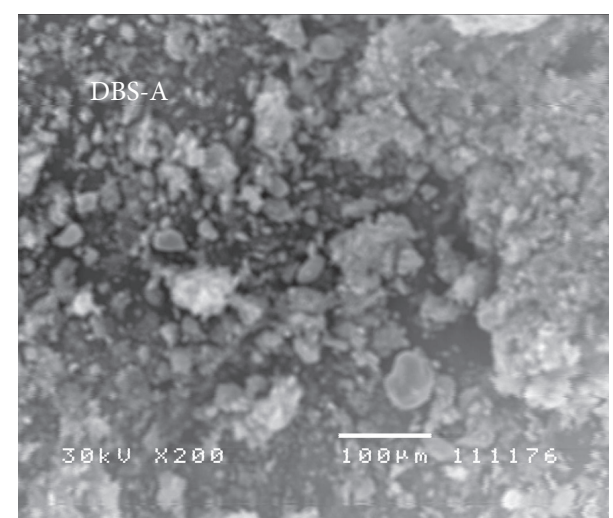

(d)

Figure 5: SEM images of the $\mathrm{TiO}_{2}$ without and with different surfactants at $\mathrm{pH}$ 3-4.

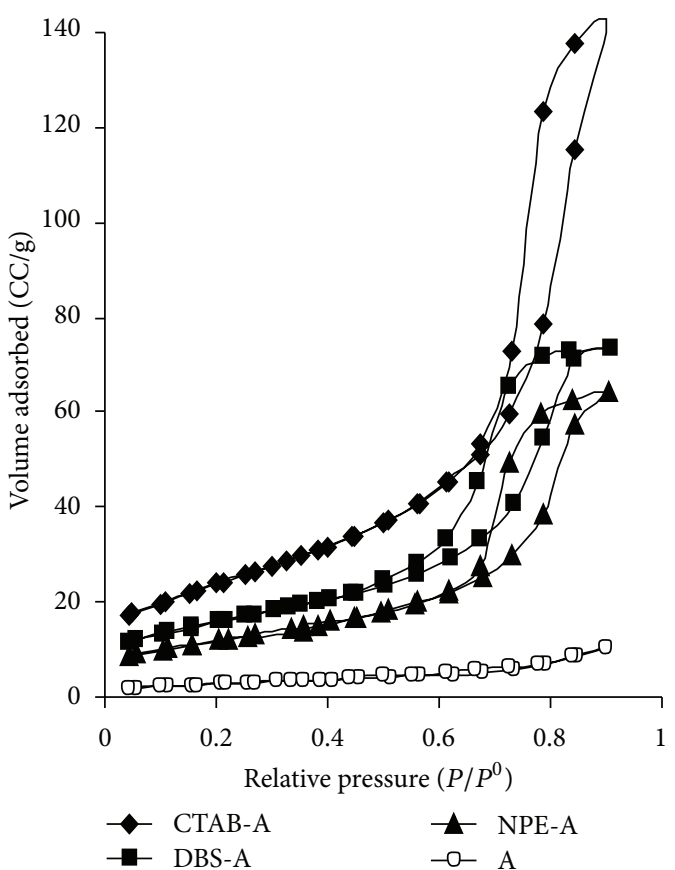

(a)

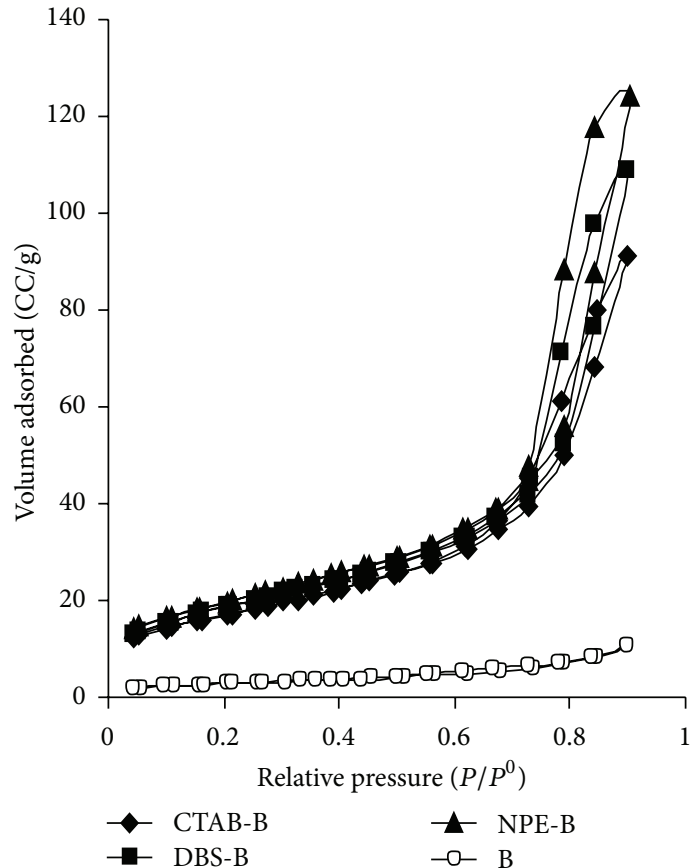

(b)

FiguRE 6: $\mathrm{N}_{2}$ adsorption/desorption isotherms for the catalysts. 


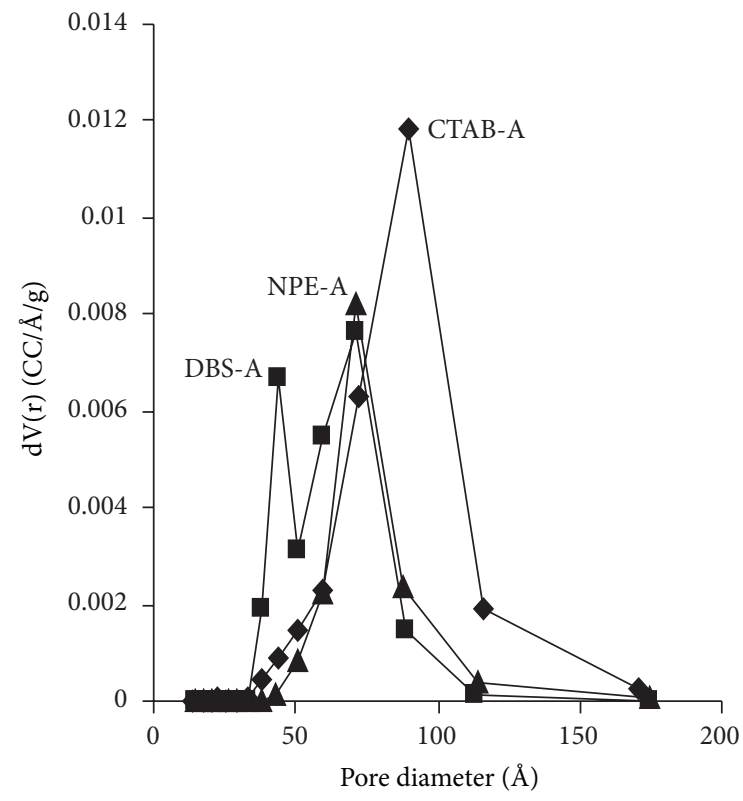

(a)

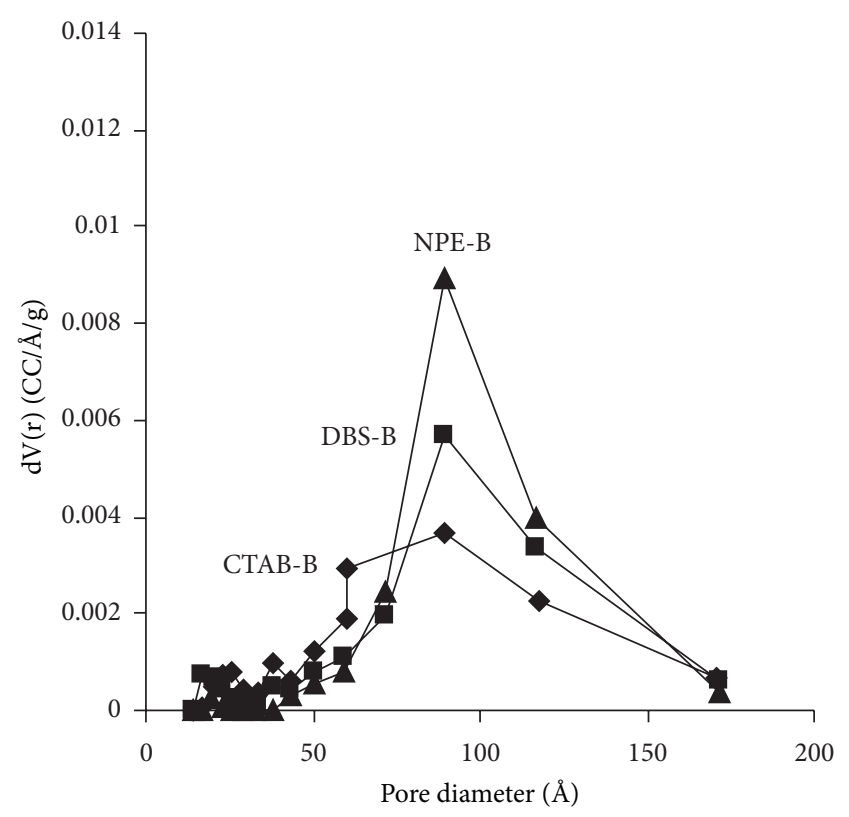

(b)

Figure 7: Pore-size distribution of $\mathrm{TiO}_{2}$ in acidic and basic media.

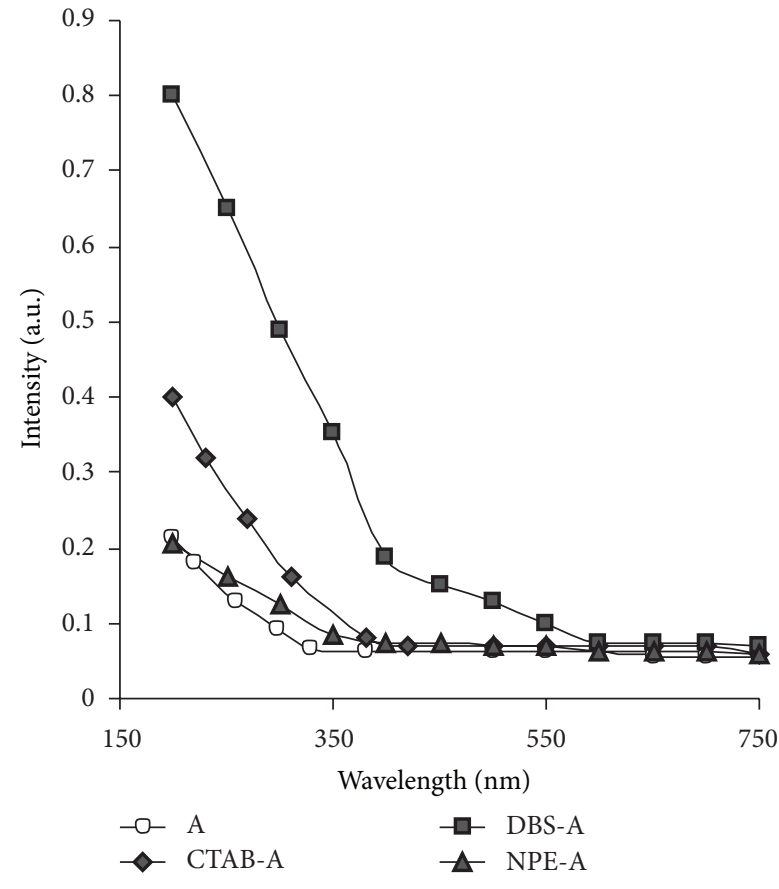

(a)

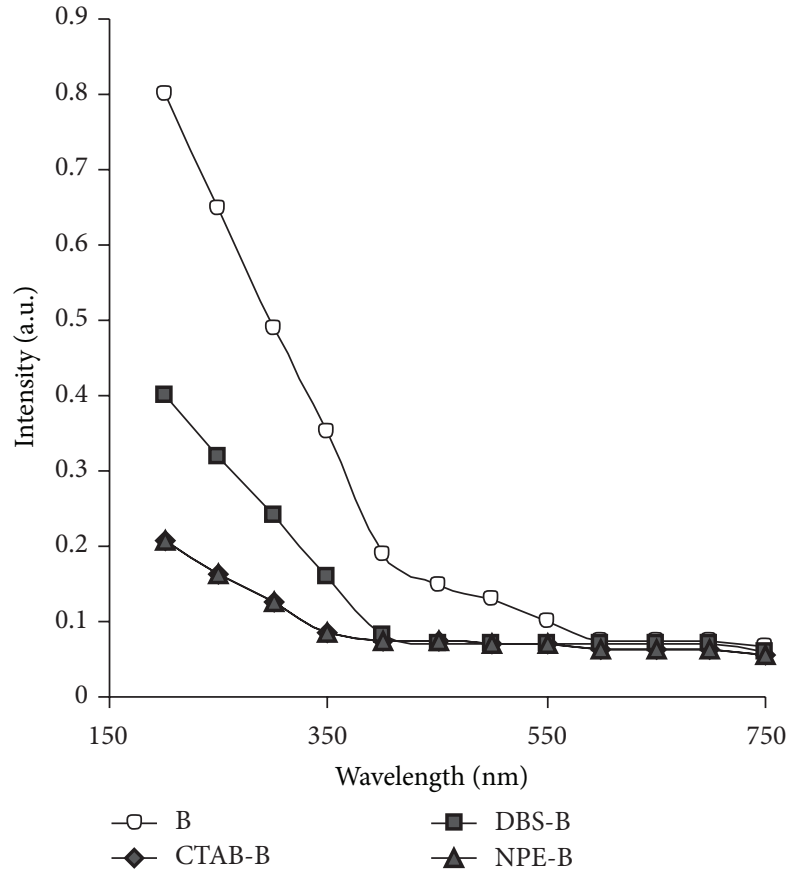

(b)

FIgURE 8: UV-vis absorption spectrum of the $\mathrm{TiO}_{2}$ catalysts.

surfactants, the photoactivities for the pollutant degradation were 37\% (A: acid medium) and 20\% (B: basic medium), respectively, whereas these values jumped by adding the surfactants to $\sim 97 \%$ using CTAB-A catalyst and to $\sim 91 \%$ using NPE-B sample. The most effective factors for photodegradation improvement were the surface area and total pore volume (mainly described by pore-size distribution).
The pore-size distribution behaviour is found to exhibit the most pronounced relevance to the catalytic activity of the current photocatalytic degradation of naphthalene. The widest mesopores are acquired by the CTAB templated acidic sample but they acquire the narrowest sizes in the pore-size distribution of the basic medium. CTAB-A catalyst gave the highest red shift in the visible range. 


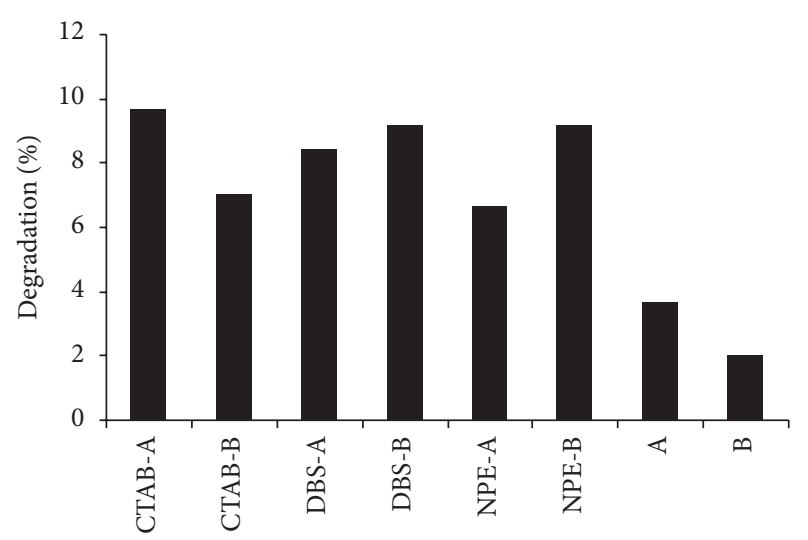

FIGURE 9: Photocatalytic activity of the current catalysts for naphthalene degradation.

\section{Conflict of Interests}

The authors declare that there is no conflict of interests regarding the publication of this paper.

\section{References}

[1] G. Tang, S. Liu, H. Tang, D. Zhang, C. Li, and X. Yang, "Template-assisted hydrothermal synthesis and photocatalytic activity of novel $\mathrm{TiO}_{2}$ hollow nanostructures," Ceramics International, vol. 39, pp. 4969-4974, 2013.

[2] T. Suprabha, H. G. Roy, J. Thomas, K. Praveen Kumar, and S. Mathew, "Microwave-assisted synthesis of titania nanocubes, nanospheres and nanorods for photocatalytic dye degradation," Nanoscale Research Letters, vol. 4, no. 2, pp. 144-152, 2009.

[3] G. Cappelletti, S. Ardizzone, C. L. Bianchi et al., "Photodegradation of pollutants in air: enhanced properties of nano- $\mathrm{TiO}_{2}$ prepared by ultrasound," Nanoscale Research Letters, vol. 4, no. 2, pp. 97-105, 2009.

[4] J. Yu, M. Jaroniec, and G. Lu, "TiO 2 photocatalytic materials," International Journal of Photoenergy, vol. 2013, Article ID 534164, 2 pages, 2013.

[5] A. Mills, N. Elliott, I. P. Parkin, S. A. O’Neill, and R. J. Clark, "Novel $\mathrm{TiO}_{2}$ CVD films for semiconductor photocatalysis," Journal of Photochemistry and Photobiology A, vol. 151, no. 1-3, pp. 171-179, 2002.

[6] D.-S. Lee and T.-K. Liu, "Preparation of $\mathrm{TiO}_{2}$ sol using $\mathrm{TiCl}_{4}$ as a precursor," Journal of Sol-Gel Science and Technology, vol. 25, no. 2, pp. 121-136, 2002.

[7] Y. K. Hwang, K. C. Lee, and Y. U. Kwon, "Nanoparticle routes to mesoporous titania thin films," Journal of Chemical Communications, vol. 18, pp. 1738-1739, 2001.

[8] N. Idrissi-Kandri, A. Ayral, M. Klotz et al., "Porous alumina thin layers using mesophase templating," Materials Letters, vol. 50, no. 2-3, pp. 57-60, 2001.

[9] J. H. Park, I. Jang, K. Song, and S. G. Oh, "Surfactants-assisted preparation of $\mathrm{TiO}_{2}-\mathrm{Mn}$ oxide composites and their catalytic activities for degradation of organic pollutant," Journal of Physics and Chemistry of Solids, vol. 74, pp. 1056-1062, 2013.

[10] A. E. Shalan, M. M. Rashad, Y. Yu, M. Lira-Cantú, and M. S. A. Mottaleb, "A facile low temperature synthesis of $\mathrm{TiO}_{2}$ nanorods for high efficiency dye sensitized solar cells," Applied Physics A, vol. 110, pp. 111-122, 2013.
[11] H. Naono, M. Hakuman, T. Tsunehisa, N. Tamura, and K. Nakai, "Formation process of MCM-41 precursor and porous texture of MCM-41," Journal of Colloid and Interface Science, vol. 224, no. 2, pp. 358-365, 2000.

[12] J. N. McDougal, D. L. Pollard, W. Weisman, C. M. Garrett, and T. E. Miller, "Assessment of skin absorption and penetration of JP-8 jet fuel and its components," Toxicological Sciences, vol. 55, no. 2, pp. 247-255, 2000.

[13] P. J. J. Alvarez and W. A. Illman, Bioreinediation and Natural Attenuation. Process Ftuiclamentals and Mathematical Models, John Wiley \& Sons, Hoboken, NJ, USA, 2006.

[14] R. N. Landau, S. C. Korré, M. Neurock, and M. T. Kline, in Catalytic Hydroprocessing of PetroleumDistillates, M. T. Oballa and S. S. Shih, Eds., pp. 421-432, Marcel Dekker, New York, NY, USA, 1994.

[15] S. J. Masten and S. H. R. Davies, "Efficacy of in-situ ozonation for the remediation of PAH contaminated soils," Journal of Contaminant Hydrology, vol. 28, no. 4, pp. 327-335, 1997.

[16] L. Zhang, P. Li, Z. Gong, and X. Li, "Photocatalytic degradation of polycyclic aromatic hydrocarbons on soil surfaces using $\mathrm{TiO}_{2}$ under UV light," Journal of Hazardous Materials, vol. 158, no. 23, pp. 478-484, 2008.

[17] X.-W. Zhang, S.-C. Shen, L. E. Yu, S. Kawi, K. Hidajat, and K. Y. Simon Ng, "Oxidative decomposition of naphthalene by supported metal catalysts," Applied Catalysis A, vol. 250, no. 2, pp. 341-352, 2003.

[18] P. R. Gogate and A. B. Pandit, "A review of imperative technologies for wastewater treatment I: oxidation technologies at ambient conditions," Advances in Environmental Research, vol. 8, no. 3-4, pp. 501-551, 2004.

[19] E. N. Ndifor, T. Garcia, and S. H. Taylor, "Naphthalene oxidation over vanadium-modified $\mathrm{Pt}$ catalysts supported on $\gamma-\mathrm{Al}_{2} \mathrm{O}_{3}$," Catalysis Letters, vol. 110, no. 1-2, pp. 125-128, 2006.

[20] A. Lair, C. Ferronato, J.-M. Chovelon, and J.-M. Herrmann, "Naphthalene degradation in water by heterogeneous photocatalysis: an investigation of the influence of inorganic anions," Journal of Photochemistry and Photobiology A, vol. 193, no. 2-3, pp. 193-203, 2008.

[21] T. Ohno, K. Tokieda, S. Higashida, and M. Matsumura, "Synergism between rutile and anatase $\mathrm{TiO}_{2}$ particles in photocatalytic oxidation of naphthalene," Applied Catalysis A, vol. 244, no. 2, pp. 383-391, 2003.

[22] H. Choi, E. Stathatos, and D. D. Dionysiou, "Synthesis of nanocrystalline photocatalytic $\mathrm{TiO}_{2}$ thin films and particles using sol-gel method modified with nonionic surfactants," Thin Solid Films, vol. 510, no. 1-2, pp. 107-114, 2006.

[23] W.-W. Jian, Z.-X. Kang, and Y.-Y. Li, "Effect of hot plastic deformation on microstructure and mechanical property of Mg-MnCe magnesium alloy," Transactions of Nonferrous Metals Society of China, vol. 17, no. 6, pp. 1158-1163, 2007.

[24] G. N. Shao, G. Elineema, D. V. Quang et al., "Two step synthesis of a mesoporous titania-silica composite from titanium oxychloride and sodium silicate," Powder Technology, vol. 217, pp. 489-496, 2012.

[25] R. Parra, M. S. Góes, M. S. Castro, E. Longos, P. R. Bueno, and J. A. Varela, "Reaction pathway to the synthesis of anatase via the chemical modification of titanium isopropoxide with acetic acid," Chemistry of Materials, vol. 20, no. 1, pp. 143-150, 2008.

[26] C. S. Lim, J. H. Ryu, D.-H. Kim, S.-Y. Cho, and W.-C. Oh, "Reaction morphology and the effect of ph on the preparation of $\mathrm{TiO}_{2}$ nanoparticles by a sol-gel method," Journal of Ceramic Processing Research, vol. 11, no. 6, pp. 736-741, 2010. 
[27] Y. Hu, H.-L. Tsai, and C.-L. Huang, "Effect of brookite phase on the anatase-rutile transition in titania nanoparticles," Journal of the European Ceramic Society, vol. 23, no. 5, pp. 691-696, 2003.

[28] T. Guohui, F. Honggang, J. Liqiang, X. Baifu, and P. Kai, "Preparation and characterization of stable biphase $\mathrm{TiO}_{2}$ photocatalyst with high crystallinity, large surface area, and enhanced photoactivity," Journal of Physical Chemistry C, vol. 112, no. 8, pp. 3083-3089, 2008.

[29] B. Guo, H. Shen, K. Shu, Y. Zeng, and W. Ning, "The study of the relationship between pore structure and photocatalysis of mesoporous $\mathrm{TiO}_{2}$," Journal of Chemical Sciences, vol. 121, no. 3, pp. 317-321, 2009.

[30] S. Nakade, M. Matsuda, S. Kambe et al., "Dependence of $\mathrm{TiO}_{2}$ nanoparticle preparation methods and annealing temperature on the efficiency of dye-sensitized solar cells," Journal of Physical Chemistry B, vol. 106, no. 39, pp. 10004-10010, 2002.

[31] K. Chen, J. Li, W. Wang, Y. Zhang, X. Wang, and H. Su, "Effects of surfactants on microstructure and photocatalytic activity of $\mathrm{TiO}_{2}$ nanoparticles prepared by the hydrothermal method," Materials Science in Semiconductor Processing, vol. 15, no. 1, pp. 20-26, 2012.

[32] M. M. Mohamed, W. A. Bayoumy, M. Khairy, and M. A. Mousa, "Synthesis and structural characterization of $\mathrm{TiO}_{2}$ and $\mathrm{V}_{2} \mathrm{O}_{5}$ / $\mathrm{TiO}_{2}$ nanoparticles assembled by the anionic surfactant sodium dodecyl sulfate," Microporous and Mesoporous Materials, vol. 97, no. 1-3, pp. 66-77, 2006.

[33] V. Štengl, V. Houšková, N. Murafa, and S. Bakardjieva, "Synthesis of mesoporous titania by homogeneous hydrolysis of titania oxo-sulfate in the presence of cationic and anionic surfactants," Ceramics, vol. 54, no. 4, pp. 368-378, 2010.

[34] S. Lowell and J. E. Shields, Powder Surface Area and Porosity, Chapman \& Hall, London, UK, 1992.

[35] S. C. Lee, H. U. Lee, S. M. Lee et al., "Preparation and characterization of bicrystalline $\mathrm{TiO}_{2}$ photocatalysts with high crystallinity and large surface area," Journal of Materials Letters, vol. 79, pp. 191-194, 2012.

[36] T.-Z. Ren, Z.-Y. Yuan, and B.-L. Su, "Surfactant-assisted preparation of hollow microspheres of mesoporous $\mathrm{TiO}_{2}$," Chemical Physics Letters, vol. 374, no. 1-2, pp. 170-175, 2003.

[37] R. Sasikala, V. Sudarsan, C. Sudakar, R. Naik, L. Panicker, and S. R. Bharadwaj, "Modification of the photocatalytic properties of self doped $\mathrm{TiO}_{2}$ nanoparticles for hydrogen generation using sunlight type radiation," International Journal of Hydrogen Energy, vol. 34, no. 15, pp. 6105-6113, 2009.

[38] D. C. Hurum, A. G. Agrios, K. A. Gray, T. Rajh, and M. C. Thurnauer, "Explaining the enhanced photocatalytic activity of Degussa P25 mixed-phase $\mathrm{TiO}_{2}$ using EPR," Journal of Physical Chemistry B, vol. 107, no. 19, pp. 4545-4549, 2003.

[39] P. R. Mishra and O. N. Srivastava, "On the synthesis, characterization and photocatalytic applications of nanostructured $\mathrm{TiO}_{2}$," Bulletin of Materials Science, vol. 31, no. 3, pp. 545-550, 2008.

[40] D. Morris, Y. Dou, J. Rebane et al., "Photoemission and STM study of the electronic structure of $\mathrm{Nb}$-doped $\mathrm{TiO}_{2}$," Physical Review B, vol. 61, no. 20, pp. 13445-13457, 2000.

[41] D. L. Liao, C. A. Badour, and B. Q. Liao, "Preparation of nanosized $\mathrm{TiO}_{2} / \mathrm{ZnO}$ composite catalyst and its photocatalytic activity for degradation of methyl orange," Journal of Photochemistry and Photobiology A, vol. 194, no. 1, pp. 11-19, 2008.

[42] A. Di Paola, G. Cufalo, M. Addamo et al., "Photocatalytic activity of nanocrystalline $\mathrm{TiO}_{2}$ (brookite, rutile and brookite-based) powders prepared by thermohydrolysis of $\mathrm{TiCl}_{4}$ in aqueous chloride solutions," Colloids and Surfaces A, vol. 317, no. 1-3, pp. 366-376, 2008.

[43] B. O’Regan and M. Grätzel, "A low-cost, high-efficiency solar cell based on dye-sensitized colloidal $\mathrm{TiO}_{2}$ films," Nature, vol. 353, no. 6346, pp. 737-740, 1991.

[44] Y. Chen, K. Wang, and L. Lou, "Photodegradation of dye pollutants on silica gel supported $\mathrm{TiO}_{2}$ particles under visible light irradiation," Journal of Photochemistry and Photobiology A, vol. 163, no. 1-2, pp. 281-287, 2004.

[45] H. Hao and J. Zhang, "Low temperature synthesis of crystalline mesoporous titania with high photocatalytic activity by posttreatment in nitric acid ethanol solution," Materials Letters, vol. 63, no. 1, pp. 106-108, 2009. 

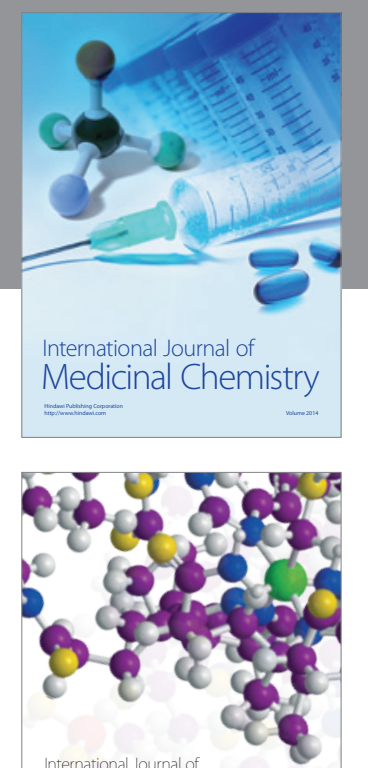

\section{Carbohydrate} Chemistry

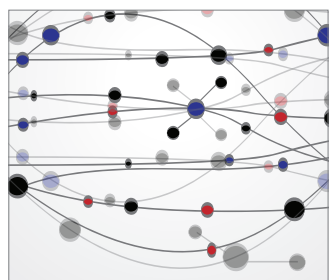

The Scientific World Journal
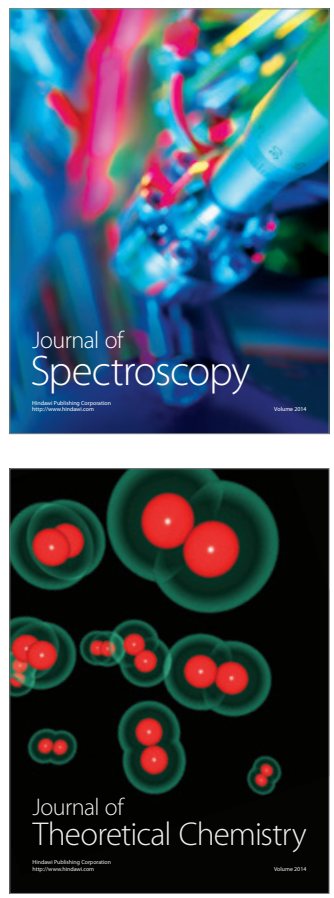
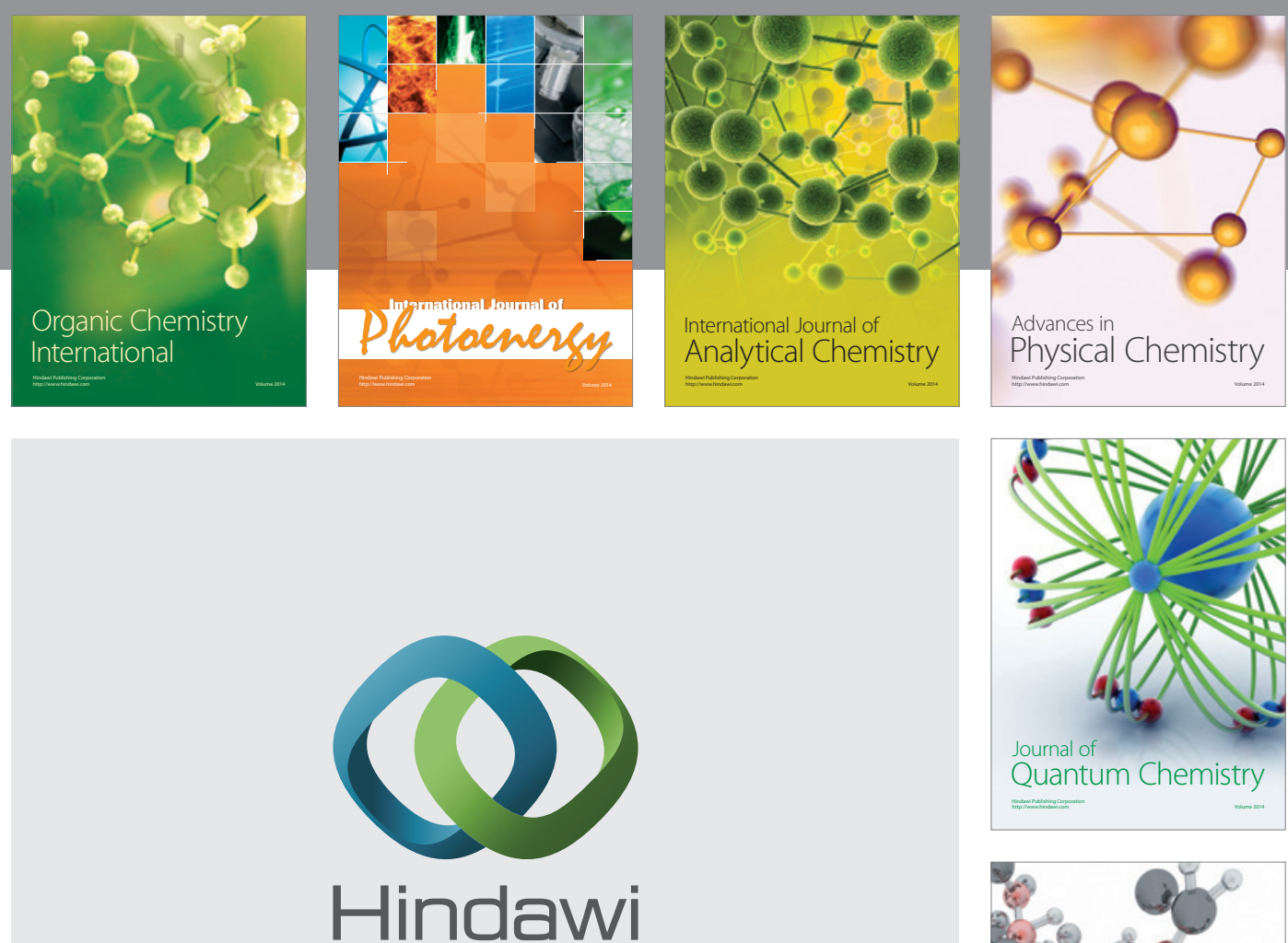

Submit your manuscripts at

http://www.hindawi.com

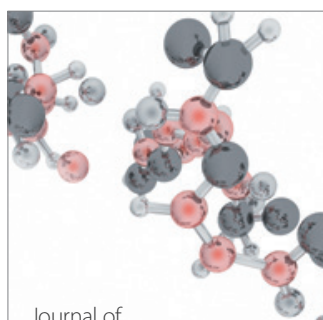

Analytical Methods

in Chemistry

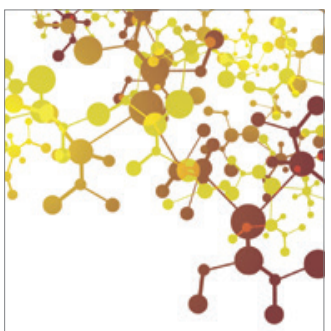

Journal of

Applied Chemistry

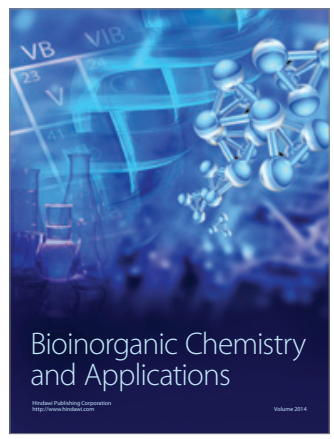

Inorganic Chemistry
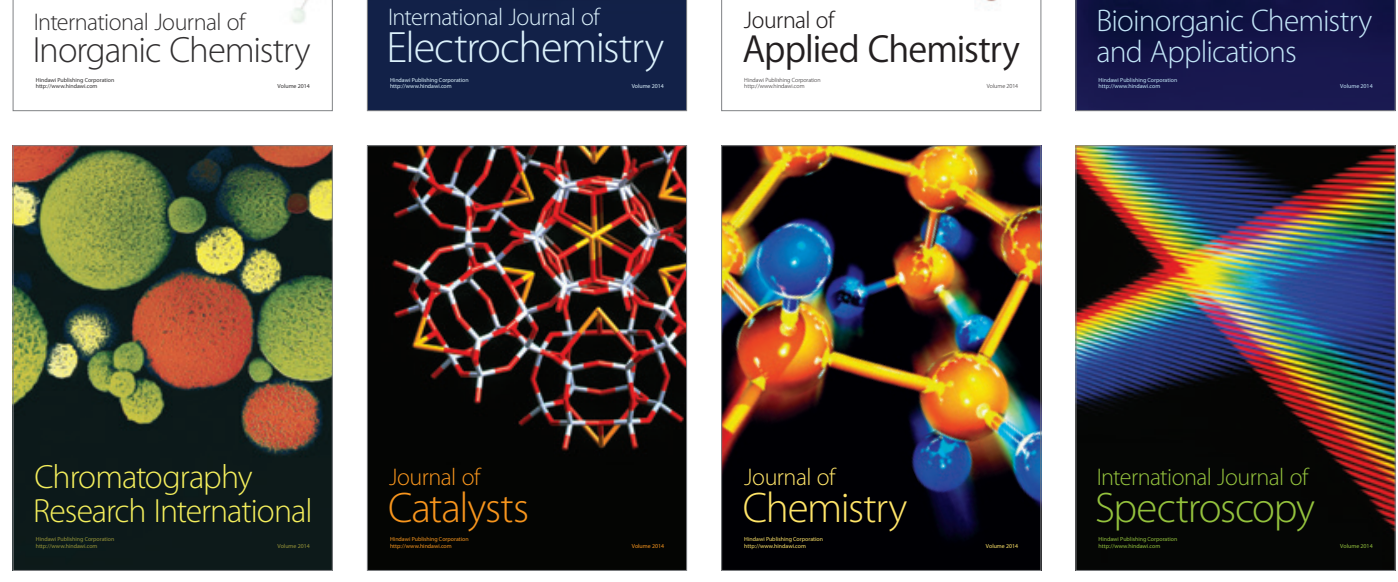